\title{
Detection Level of Salivary Survivin in Patients with OSCC
}

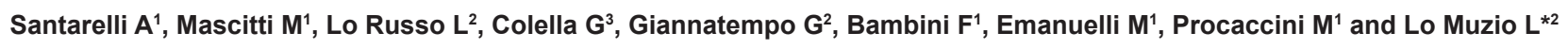

${ }^{1}$ Department of Clinical Specialistic and Dental Sciences, Marche Polytechnic University, Ancona, Italy

${ }^{2}$ Department of Clinical and Experimental Medicine, Foggia University, Foggia, Italy

${ }^{3}$ Department of Medical, Surgical and Dental Specialities, SUN University, Naples, Italy

\begin{abstract}
Introduction: Survivin is a member of the Inhibitor of Apoptosis (IAP) proteins family, broadly expressed in most solid and haematological malignancies, but almost undetectable in normal adult tissues. Regarding Oral Squamous Cell Carcinoma (OSCC), Survivin expression seems to be correlated with aggressive phenotype and unfavorable outcome. In this work, the effectiveness of Survivin detection in saliva samples as diagnostic tool was investigated.

Methods: 55 saliva samples from patients with histological diagnosis of OSCC and 30 samples from healthy controls matched for age and gender were collected. All samples from OSCC were collected before therapy. Saliva was analyzed using Assay Designs human Total Survivin TiterZyme® Enzyme Immunometric Assay (EIA) kit for Survivin detection and quantification. Survivin concentration $(\mathrm{pg} / \mathrm{ml})$ was studied in relationship to clinical data. Univariate statistical analysis was performed.
\end{abstract}

Results: $35 / 55$ (63.6\%) among OSCC patients were found to be positive for surviving expression in saliva vs $12 / 30(40 \%)$ among health controls; but the mean value was found to be higher in OSCC group $(8,69 \mathrm{pg} / \mathrm{ml} \pm 10,15$ vs $2.44 \mathrm{pg} / \mathrm{ml} \pm 4.22)$ reaching statistical significance $(p<0.05)$. Moreover, samples from patients at an early stage $(\mathrm{I}+\mathrm{II})$ displayed a lower content of salivary Survivin than those at advanced stage $(\mathrm{III}+\mathrm{IV})(7.09 \mathrm{pg} / \mathrm{ml} \pm 8.59 \mathrm{vs} 8.13$ $\mathrm{pg} / \mathrm{ml} \pm 10.94)$. In addition, cases characterized by lymph node metastasis showed a higher surviving concentration (9.38 pg/ml \pm 11.26$)$ than cases without metastasis $(5.77 \mathrm{pg} / \mathrm{ml} \pm 8.21)$.

Discussion: Salivary Survivin seems to be an interesting biomarker for OSCC, but its use as a single marker may be not sufficient for the early diagnosis of OSCC.

Keywords: Survivin; OSCC; Saliva; Early diagnosis

Abbreviations: OSCC: Oral Squamous Cell Carcinoma; IAP: Inhibitor of Apoptosis; EIA: Enzyme Immunometric Assay

\section{Introduction}

Oral Squamous Cell Carcinoma (OSCC) is the most common malignant tumor of the oral cavity, representing more than $90 \%$ of all cancers of this district [1,2]. It is the eighth most common cancer worldwide, even if epidemiologic variations between different geographic regions have to be taken into account $[3,4]$. In spite of the advances accomplished in oncology and surgery, the mortality rates in the last 20 years remain almost unchanged, with the 5-year survival rate ranging from 35 to $50 \%$ [5]. The diagnostic delay represents one of the principal reasons for the OSCC poor prognosis. Indeed, making the diagnosis at an advanced stage (ie. Stage III or IV) drastically reduces the patient's life expectancy [6].

Thus, discover of sensitive and specific molecular tumor markers for early cancer detection may improve the survival rates of OSCC.

Survivin, a member of Inhibitors of Apoptosis protein family (IAP) [7], is a $16.5 \mathrm{kDa}$ protein composed of 142 -amino acid encoded by a gene located on the 17q25 chromosome [8]. This protein controls chromosome spindle checkpoint assembly, suggesting that the primary function of Survivin is in controlling cell division, rather than apoptosis inhibition [9]. Survivin exhibits low or undetectable expression levels in most non-proliferating adult tissues, but is broadly expressed in a wide variety of cancers [10], suggesting it has been implicated in both control of cell survival and regulation of mitosis in tumor cells [11]. The levels of Survivin in OSCC tissues result greatly higher than those in normal mucosa [12], and its degree of expression is directly related to aggressive phenotype and poor prognosis [13-15]. Due to these features, surviving detection could be employed for diagnostic purposes. Indeed, recent studies showed a possible role for Survivin as a sensitive marker for the noninvasive diagnosis of bladder cancer [1619]. Urine Survivin resulted to be a strong, independent predictor of the presence of bladder cancer and higher tumor grade [19].

In recent years, a growing interest towards salivary markers led to the study of many molecules, looking for a potential candidate as a biomarker that could provide prognostic and/or diagnostic information in OSCC [20].

In the present study the salivary levels of Survivin in patients with OSCC were compared with those in healthy subjects, aiming to assess the effectiveness of salivary Survivin detection as a diagnostic marker for oral squamous cell carcinoma.

\section{Materials and Methods}

\section{Selection of cases}

A total of 55 patients with primary OSCC were recruited from Department of Medical, Surgery and Dental Specialties, SUN University, Naples, Italy.All participants approved the informed consent to donate saliva for experiments. None of patients had been treated

*Corresponding author: Prof. Lorenzo Lo Muzio, Via Rovelli, 48 - 71122 Foggia - Italy; Tel: 00390881 588090; Fax: 00390881 588081; E-mail: llomuzio@tin.it

Received June 04, 2013; Accepted September 11, 2013; Published September 18,2013

Citation: Santarelli A, Mascitti M, Lo Russo L, Colella G, Giannatempo G, et al. (2013) Detection Level of Salivary Survivin in Patients with OSCC. J Carcinogene Mutagene S5: 004. doi:10.4172/2157-2518.S5-004

Copyright: (c) 2013 Santarelli A, et al. This is an open-access article distributed under the terms of the Creative Commons Attribution License, which permits unrestricted use, distribution, and reproduction in any medium, provided the original author and source are credited. 


\begin{tabular}{|c|c|c|}
\hline \multicolumn{2}{|c|}{ Patients characteristics } \\
\hline \multirow{2}{*}{ Gender } & - M & 38 \\
& - F & 17 \\
\hline \multirow{2}{*}{ Age } & $-<$ = 65 yrs & 29 \\
& $->65$ yrs & 26 \\
\hline \multirow{3}{*}{ Location } & - Gum & 9 \\
& - Floor & 10 \\
& - Tongue & 20 \\
& - Lip & 4 \\
& - Cheek & 3 \\
Stage & - Palate & 4 \\
& - Other & 5 \\
\hline \multirow{2}{*}{ Metastasis } & - I & 10 \\
& - II & 13 \\
& - III & 10 \\
\hline \multirow{2}{*}{ Grade } & - IV & 22 \\
& - N- & 27 \\
& - N+ & 28 \\
\hline
\end{tabular}

Table 1: Patients characteristics

previously. Saliva samples were collected prior to any curative therapy (ie. surgery with or without radiotherapy or/and chemotherapy). No case in this study concerned patients with a history of prior malignancy, immunodeficiency, autoimmune disorders, hepatitis or HIV infection. Clinical data were reviewed to record sex and age of the patients, and site and size of the lesions. The group consisted of 38 males and 17 females with a mean range of 62 years (range 29-85). The characteristics of patients and their tumors are showed in Table 1.

In addition, 30 healthy individuals, 21 males and 9 females with a mean range of 52 years (range 31-69), were enrolled as control from patients who had undergone routine oral surgical procedures. All participants approved the informed consent to donate saliva for experiments.

\section{Saliva collection and preparation}

Patients were asked to refrain from eating, drinking, smoking and oral hygiene procedures for at least 1 hour prior to saliva collection [21]. $5 \mathrm{ml}$ of whole saliva samples were collected from each subject. Firstly, they were asked to rinse their mouth with water and then expectorate saliva into $50 \mathrm{ml}$ centrifuge tube. Collection tubes were immediately centrifuged at $5000 \mathrm{~g}$ for 5 minutes at $+4^{\circ} \mathrm{C}$ to remove cell pellets and debris. Surnatants were then divided into 2 aliquots and stored at $-80^{\circ} \mathrm{C}$ for subsequent analysis.

\section{Enzyme-linked immunosorbent assay}

Enzyme-linked immunosorbent assay (Total Survivin Titerzyme Enzyme Immunometric Assay, Assay Designs, Ann Arbor, MI USA) was performed to determine survivin levels in the saliva samples of OSCC $(n=55)$ and control patients $(n=30)$. Undiluted samples were loaded, in duplicate, onto a 96-microtiter plate coated with antihuman Survivin monoclonal antibody. In order to quantify Survivin levels, in each experiment a standard curve was created with increasing quantities of purified recombinant Survivin. After incubation at room temperature on a plate shaker for 1 hour at $500 \mathrm{rpm}$, the excess samples or standards were washed out and a rabbit polyclonal antibody to Survivin was added.

After another 1-hour incubation, the excess antibody was washed out and goat anti-rabbit IgG conjugated to Horseradish peroxidase was added. After 30 minutes incubation, excess conjugate was washed out and 3,3,5,5'-tetramethylbenzidine substrate solution was added. After another 30 minutes incubation, the enzyme reaction was stopped and the colour generated was immediately read at $450 \mathrm{~nm}$. The measured optical density was directly proportional to the concentration of Survivin in either standards or samples.

\section{Statistical analysis}

Data were analysed using GraphPad Prism software version 6.00 for Windows (GraphPad Software, San Diego California USA, www. graphpad.com). Significant differences $(\mathrm{p}<0.05)$ between groups were determined using one-way analysis of variance and the StudentNewman-Keuls-test. Contingency table and Fisher's exact test were used to assess the sensitivity, specificity, positive and negative predictive value of salivary Survivin test. All data were presented as mean \pm standard deviation.

\section{Results}

Salivary Survivin levels in OSCC patients and in controls were measured using a specific ELISA test. The mean level of Survivin for OSCC patients $(\mathrm{n}=55)$ was $8.69 \mathrm{pg} / \mathrm{ml} \pm 10.15$, whereas it was $2.44 \mathrm{pg} /$ $\mathrm{ml} \pm 4.22$ for the control subjects $(\mathrm{n}=30)$. This difference in Survivin levels between OSCC cases and controls was statistically significant $(\mathrm{p}<0.05)$, as shown in Figure 1.

Using the value obtained from the average of Survivin levels in controls as cutoff, the sensitivity and specificity values of Survivin salivary levels in OSCC patients were $63.64 \%$ and $73.33 \%$ respectively, whereas positive and negative predictive value were $81.4 \%$ and $52.38 \%$.

The association of Survivin levels in OSCC patients with age, gender, Grading, Staging and lymph node metastasis is shown in Table 2. Results showed that salivary levels of Survivin in OSCC patients were increased in advanced stages (III + IV $)(8.13 \mathrm{pg} / \mathrm{ml} \pm 10.94)$ compared to the early stages of disease $(\mathrm{I}+\mathrm{II})(7.09 \mathrm{pg} / \mathrm{ml} \pm 8.59)$, even if this difference was not statistically significant.

Whereas, differences in Survivin levels between early stages of OSCC and control subjects were statistically significant $(2.44 \mathrm{pg} / \mathrm{ml} \pm$ $4.22 \mathrm{vs} 7.09 \mathrm{pg} / \mathrm{ml} \pm 8.59, \mathrm{p}=0.0156)$.

The presence of lymph node metastases was associated with increased levels of Survivin $(9.38 \mathrm{pg} / \mathrm{ml} \pm 11.26 \mathrm{vs} 5.77 \mathrm{pg} / \mathrm{ml} \pm 8.21)$,

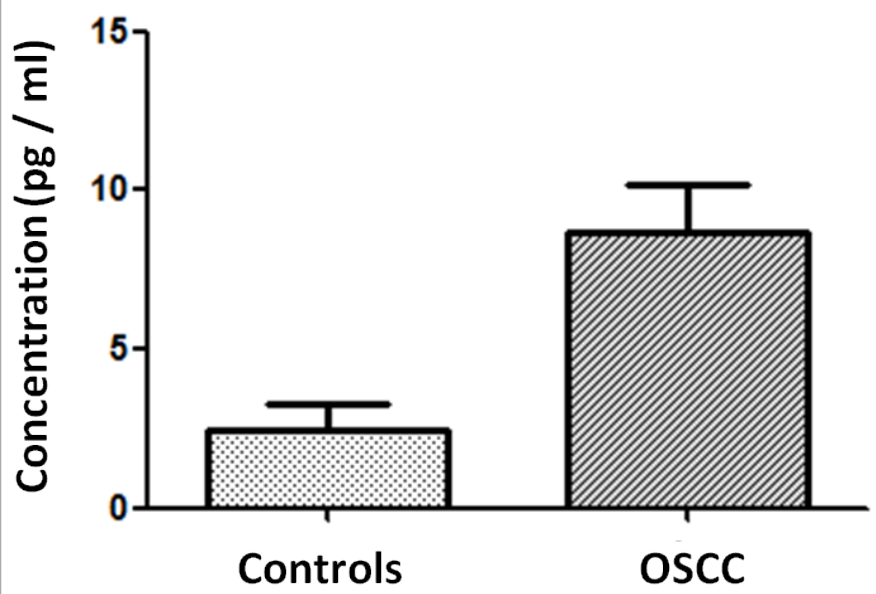

Figure 1: Mean value of Survivin. 


\begin{tabular}{|c|c|c|c|c|}
\hline Variables & No. & $\begin{array}{l}\text { Mean Survivin } \\
\text { levels (pg/ml) }\end{array}$ & $p$ value & $\begin{array}{l}\text { Statistical } \\
(p<0.05)\end{array}$ \\
\hline Cases & 55 & 8.69 & & \\
\hline $\begin{array}{l}\text { Age } \\
</=65 \mathrm{yrs} \\
>65 \mathrm{yrs}\end{array}$ & $\begin{array}{l}29 \\
26\end{array}$ & $\begin{array}{l}7.39 \\
6.23\end{array}$ & 0.6519 & $\mathrm{No}^{1}$ \\
\hline \multicolumn{5}{|l|}{ Sex } \\
\hline \multirow{2}{*}{$\begin{array}{l}\text { Male } \\
\text { Female }\end{array}$} & 38 & 7.23 & 0.5201 & $\mathrm{No}^{1}$ \\
\hline & 17 & 9.16 & & \\
\hline \multirow{2}{*}{$\begin{array}{l}\text { Grade } \\
\text { G1 } \\
\text { G2 } \\
\text { G3 }\end{array}$} & & & & \\
\hline & $\begin{array}{l}26 \\
16 \\
13\end{array}$ & $\begin{array}{l}5.66 \\
7.18 \\
3.43 \\
\end{array}$ & 0.6494 & $\mathrm{No}^{2}$ \\
\hline \multirow{2}{*}{$\begin{array}{l}\text { Stage } \\
\text { I + II } \\
\text { III + IV }\end{array}$} & & & & \\
\hline & $\begin{array}{l}23 \\
32\end{array}$ & $\begin{array}{l}7.09 \\
8.13\end{array}$ & 0.9614 & $\mathrm{No}^{1}$ \\
\hline \multicolumn{5}{|l|}{ Metastasis } \\
\hline $\begin{array}{l}\mathrm{N}- \\
\mathrm{N}+\end{array}$ & $\begin{array}{l}27 \\
28\end{array}$ & $\begin{array}{l}5.77 \\
9.38\end{array}$ & 0.2430 & $\mathrm{No}^{1}$ \\
\hline
\end{tabular}

'Student-Newmann-Keuls' test.

'One-way Analysis of Variance (ANOVA) and Student-Newman-Keuls Multiple Comparisons Test

Table 2: Statistical analysis of Survivin levels in OSCC patients.

without a statistically significant correlation. As regards the grading, no correlation with the salivary levels of Survivin was found.

\section{Discussion}

OSCC is the leading malignant neoplasm in the oral cavity, with the 5-years survival rate of less than 50\% [5]. Despite advances in oncology and surgery treatments, this trend remained unchanged over the last decades mainly due to diagnostic delay, which leads to make the diagnosis at an advanced stage, drastically reducing effectiveness of therapies and life expectancy [6]. Thus, the identification of possible markers for early cancer detection is still a mandatory issue.

Biomarkers for early cancer detection must fulfill several criteria: 1) it can be objectively measured; 2) must be measurable in small specimens; 3) must be altered in high-risk tissues, but not in normal tissues; 4) must be altered in early stages during cancer development [20]. Moreover, markers detectable also in body fluids (as blood, urine or saliva) would be preferable over tissue markers. Indeed, body fluids have several advantages that make them good choice for disease screening and diagnosis, like ease of collection, low-invasive procedure, low cost, and multiple sampling for monitoring over time [22]. Furthermore, saliva, over the other body fluids, has the following advantages: non-invasive easy collection and a low content in cells, DNA, proteins and inhibitory substances [23].

For the above stated reasons, in recent years, a growing interest towards salivary markers led to the study of many molecules, looking for a potential candidate as a biomarker that could provide prognostic and/or diagnostic information in OSCC [20].

Several studies have shown that saliva from patients with OSCC contains high levels of different proteins such as IL-1, IL-6, IL-8, CD44, CEA, $\alpha$-defensin- 1 and TNF- $\alpha$ [24-28], as well as fibronectin, fragments of cytokeratin 19, tissue polypeptide antigen (TPA), endothelin-1, Cyfra 21-1, cancer antigens CA125, M2bp, MRP14, profilin, CD59 and catalase, considered as potential markers for oral cancer [24-30].

Patients with premalignant oral lesions show levels of TNF- $\alpha$, IL1-a, IL-6 and IL-8 lower than the values measured in patients with
OSCC, while the levels of these pro-inflammatory cytokines are higher compared to healthy control samples $[25,29,31]$. There are contrasting opinions about the differences in the expression of Survivin between normal mucosa and potentially malignant lesions. Some authors have found that Survivin expression is presented at a low rate both in normal oral mucosa and in leukoplakias [32]. Other surveys report significant difference between potentially malignant and normal mucosa [33]. Several authors agree in maintaining that Survivin expression rates can be considered a putative predictive value that appears among lesions evolving into OSCC compared with lesions not evolving in malignancies $[34,35]$.

Strong evidence supports the general consensus that Survivin overexpression is a constant findings in OSCC, thus making Survivin a potential candidate as a useful biomarker in OSCC.

Hence, in the present study the possibility of using Survivin as salivary biomarker was evaluated. Indeed, Survivin resulted widely expressed in many types of cancers [10], including OSCC [13,32], while showed low or undetectable expression levels in most non-proliferating adult tissues [10]

In this work the salivary levels of Survivin in 55 patients with OSCC at different stages were compared with the levels of this protein in 30 healthy subjects. The results of the present study indicate that the Survivin levels in patients with OSCC are significantly higher than those of healthy subjects.

Furthermore, the differences in Survivin levels between early stages of OSCC and control subjects were statistically significant, confirming the potential usefulness of this protein as an early diagnostic tool.

Given that Survivin is a non-secreted protein, these findings suggest that the measured Survivin in saliva derives from the cancer cells released into saliva.

To the best of our knowledge, this is the first study dealing with salivary Survivin in OSCC. However, previous works on urine Survivin confirmed that cancer patients might have higher levels of detectable Survivin in body fluids respect to healthy control subjects [19]. Furthermore, it has recently been shown that concentrations of salivary MMP- 1 and MMP-3 are higher in patients with OSCC than in samples from healthy controls and that these concentrations increase proportionally with increasing stage of the disease [36].

The salivary levels of Survivin results to be higher in advanced stages $(\mathrm{III}+\mathrm{IV})$ and in N+ cases, compared to the early stages (I + II) and $\mathrm{N}$ - cases, although these differences were not statistically significant. These results are in agreement with other studies that showed lack of correlation between tissue Survivin expression and staging or grading in OSCC [13]. It means that Survivin may be considered an independent predictor of the presence of oral cancer regardless of cancer stage and grade.

Considering the mean value of the Survivin levels of control subjects as the cut-off, the sensitivity and the specificity were respectively $63.64 \%$ and $73.33 \%$. The same sensitivity value was reached in other works that have measured the levels of urinary Survivin in bladder cancer [19], even if specificity was lower. Differences in sample size, body fluids employed and type of cancer must be taken into account for explanation. Moreover, among other body fluids, saliva has the less standardized method of collection, thus may leading to variations in biomarkers quantification.

These considerations, combined with the limited number of 
Citation: Santarelli A, Mascitti M, Lo Russo L, Colella G, Giannatempo G, et al. (2013) Detection Level of Salivary Survivin in Patients with OSCC. J Carcinogene Mutagene S5: 004. doi:10.4172/2157-2518.S5-004

patients enrolled in this study, may explain the high standard deviation found in OSCC patients. The presence of a high standard deviation can limit the diagnostic relevance of the measurement of salivary Survivin as single biomarker.

However, in the identification of potential salivary biomarkers, it was possible to reach higher values only by the use of genomic and proteomic technologies and the combination of a panel of different markers. Indeed, $\mathrm{Li}$ et al. reported that 7 transcripts, of the genes DUSP1, H3F3A, IL-1 $\beta$, IL-8, OAZ1, SAT and S100P, were elevated in patients with OSCC and lower in healthy controls [37]. The combination of these biomarkers showed $91 \%$ of Sensitivity and specificity [37].

However, one of the major limits for the development of a salivary test there is no biologically justified cutoff value for levels of Survivin in patients with cancer, including oral cancer. Further studies in larger cohorts of patients would be necessary to establish biological and clinically relevant cut points.

Even considering the above cited limitations of the present study, Survivin seems to be an interesting salivary biomarker for noninvasive OSCC diagnosis. However, present data should be considered preliminary, and thus the use of Survivin as a single marker may be not sufficient for the early diagnosis of OSCC. Further investigations with larger samples and multiple biomarkers evaluation are required to clarify this issue.

\section{References}

1. Lingen M, Sturgis EM, Kies MS (2001) Squamous cell carcinoma of the head and neck in nonsmokers: clinical and biologic characteristics and implications for management. Curr Opin Oncol 13: 176-182.

2. Petersen PE (2005) Strengthening the prevention of oral cancer: the WHO perspective. Community Dent Oral Epidemiol 33: 397-399.

3. Moore S, Johnson N, Pierce A, Wilson D (1999) The epidemiology of lip cancer: a review of global incidence and aetiology. Oral Dis 5: 185-195.

4. Moore SR, Johnson NW, Pierce AM ,Wilson DF (2000) The epidemiology of mouth cancer: a review of global incidence. Oral Dis 6: 65-74.

5. Parkin DM, Bray F, Ferlay J, Pisani P (2005) Global cancer statistics, 2002. CA Cancer J Clin 55: 74-108.

6. McDowell JD (2006) An overview of epidemiology and common risk factors for oral squamous cell carcinoma. Otolaryngol Clin North Am 39: 277-294.

7. Ambrosini G, Adida C, Altieri DC (1997) A novel anti-apoptosis gene, survivin expressed in cancer and lymphoma. Nat Med 3: 917-921.

8. Chantalat L, Skoufias DA, Kleman JP, Jung B, Dideberg O, et al. (2000) Crystal structure of human survivin reveals a bow tie-shaped dimer with two unusual alpha-helical extensions. Mol Cell 6: 183-189.

9. Okada H, Bakal C, Shahinian A, Elia A, Wakeham A, et al. (2004) Survivin loss in thymocytes triggers p53-mediated growth arrest and p53-independent cell death. J Exp Med 199: 399-410.

10. Kelly RJ, Lopez-Chavez A, Citrin D, Janik JE, Morris JC (2011) Impacting tumor cell-fate by targeting the inhibitor of apoptosis protein survivin. Mol Cancer 10 35.

11. Pennati M, Folini M, Zaffaroni N (2007) Targeting survivin in cancer therapy: fulfilled promises and open questions. Carcinogenesis 28: 1133-1139.

12. Lo Muzio L, Staibano S, Pannone G, Mignogna MD, Mariggiò A, et al. (2001) Expression of the apoptosis inhibitor survivin in aggressive squamous cell carcinoma. Exp Mol Pathol 70: 249-254.

13. Lo Muzio L, Pannone G, Staibano S, Mignogna MD, Rubini C, et al. (2003) Survivin expression in oral squamous cell carcinoma. Br J Cancer 89: 22442248.

14. Su L, Wang Y, Xiao M, Lin Y, Yu L (2010) Up-regulation of survivin in oral squamous cell carcinoma correlates with poor prognosis and chemoresistance. Oral Surg Oral Med Oral Pathol Oral Radiol Endod 110: 484-491.
15. Lo Muzio L, Farina A, Rubini C, Pezzetti F, Stabellini G, et al. (2005) Survivin as prognostic factor in squamous cell carcinoma of the oral cavity. Cancer Let 225: $27-33$.

16. Moore M (2001) Urine detection of survivin and diagnosis of bladder cancer. Insur Med 33: 202-203.

17. Smith SD, Wheeler MA, Plescia J, Colberg JW, Weiss RM, et al. (2001) Urine detection of survivin and diagnosis of bladder cancer. JAMA 285: 324-328.

18. Ohsawa I, Nishimura T, Kondo Y, Kimura G, Satoh M, et al. (2004) Detection of urine survivin in 40 patients with bladder cancer. J Nippon Med Sch 71 379-383.

19. Shariat SF, Casella R, Khoddami SM, Hernandez G, Sulser T, et al. (2004) Urine detection of survivin is a sensitive marker for the noninvasive diagnosis of bladder cancer. J Urol 171: 626-630.

20. Wu JY, Yi C, Chung HR, Wang DJ, Chang WC, et al. (2010) Potential biomarkers in saliva for oral squamous cell carcinoma. Oral Oncol 46: 226-231.

21. Arellano-Garcia ME, Hu S, Wang J, Henson B, Zhou H, et al. (2008) Multiplexed immunobead-based assay for detection of oral cancer protein biomarkers in saliva. Oral Dis 14: 705-712.

22. Nunes DN, Kowalski LP, Simpson AJ (2000) Detection of oral and oropharyngeal cancer by microsatellite analysis in mouth washes and lesion brushings. Oral Oncol 36: 525-528.

23. Zimmermann BG, Park NJ, Wong DT (2007) Genomic targets in saliva. Ann N Y Acad Sci 1098: 184-191.

24. Chen YC, Li TY, Tsai MF (2002) Analysis of the saliva from patients with oral cancer by matrix-assisted laser desorption/ionization time-of-flight mass spectrometry. Rapid Commun Mass Spectrom 16: 364-369.

25. St John MA, Li Y, Zhou X, Denny P, Ho CM, et al. (2004) Interleukin 6 and interleukin 8 as potential biomarkers for oral cavity and oropharyngea squamous cell carcinoma. Arch Otolaryngol Head Neck Surg 130: 929-935.

26. Rhodus NL, Ho V, Miller CS, Myers S, Ondrey F (2005) NF-kappaB dependent cytokine levels in saliva of patients with oral preneoplastic lesions and ora squamous cell carcinoma. Cancer Detect Prev 29: 42-45.

27. Franzmann EJ, Reategui EP, Pedroso F, Pernas FG, Karakullukcu BM, et al (2007) Soluble CD44 is a potential marker for the early detection of head and neck cancer. Cancer Epidemiol Biomarkers Prev 16: 1348-1355.

28. Mizukawa N, Sugiyama K, Fukunaga J, Ueno T, Mishima K, et al. (1998) Defensin-1, a peptide detected in the saliva of oral squamous cell carcinoma patients. Anticancer Res 18: 4645-4649.

29. Rhodus NL, Cheng B, Myers S, Miller L, Ho V, et al. (2005) The feasibility of monitoring NF-kappaB associated cytokines: TNF-alpha, IL-1alpha, IL-6, and IL-8 in whole saliva for the malignant transformation of oral lichen planus. Mol Carcinog 44: 77-82.

30. Shpitzer T, Hamzany Y, Bahar G, Feinmesser R, Savulescu D, et al. (2009) Salivary analysis of oral cancer biomarkers. Br J Cancer 101: 1194-1198.

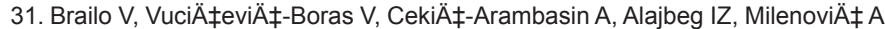
et al. (2006) The significance of salivary interleukin 6 and tumor necrosis factor alpha in patients with oral leukoplakia. Oral Oncol 42: 370-373.

32. Lodi G, Franchini R, Bez C, Sardella A, Moneghini L, et al. (2010) Detection of survivin mRNA in healthy oral mucosa, oral leucoplakia and oral cancer. Oral Dis 16: 61-67.

33. Tanaka C, Uzawa K, Shibahara T, Yokoe H, Noma H, et al. (2003) Expression of an inhibitor of apoptosis, survivin, in oral carcinogenesis. J Dent Res 82: 607-611.

34. Lo Muzio L, Pannone G, Leonardi R, Staibano S, Mignogna MD, et al. (2003) Survivin, a potential early predictor of tumor progression in the oral mucosa. $J$ Dent Res 82: 923-928.

35. Lin CY, Hung HC, Kuo RC, Chiang CP, Kuo MY (2005) Survivin expression predicts poorer prognosis in patients with areca quid chewing-related ora squamous cell carcinoma in Taiwan. Oral Oncol 41: 645-654.

36. Stott-Miller M, Houck JR, Lohavanichbutr P, Méndez E, Upton MP, et al. (2011) Tumor and salivary matrix metalloproteinase levels are strong diagnostic markers of oral squamous cell carcinoma. Cancer Epidemiol Biomarkers Prev 20: $2628-2636$.

37. Li Y, St John MA, Zhou X, Kim Y, Sinha U, et al. (2004) Salivary transcriptome diagnostics for oral cancer detection. Clin Cancer Res 10: 8442-8450. 